\title{
Ethylene Production and Expression of Two Ethylene Biosynthetic Genes in Senescing Flowers of Hosta ventricosa
}

\author{
Xiaoxian Zhu, Haitao Hu, Weidong Guo, Jianhua Chen, Changchun Wang, and Ling Yang* \\ College of Chemistry and Life Sciences, Zhejiang Normal University, Jinhua, Zhejiang 321004, China
}

\begin{abstract}
Senescence of Hosta ventricosa flowers was firstly characterized as ethylene-sensitive since the deterioration of the tepal was accompanied by increased endogenous ethylene biosynthesis. The full-length cDNAs and DNAs of 1-aminocyclopropane-1carboxylic acid (ACC) synthase (ACS) and ACC oxidase (ACO) involved in ethylene biosynthesis were cloned from $H$. ventricosa flowers. The HvACS ORF with $1347 \mathrm{bp}$ and two introns, encoded a polypeptide of 448 amino acids showing 79\% homology with that in Musa acuminata. The HvACO ORF contained 957 bp and three introns, encoding a 318-residue polypeptide showing $83 \%$ homology with that in Narcissus tazetta. The timing of the induction of HvACS expression was in correspond to the timing of the increase in ethylene production, and that the up-regulation of $H v A C O$ transcript was closely correlated with an elevated ethylene production, but underwent a down-regulation in wounded leaves with elevated ethylene emission. The results, together with expression analysis in vegetative tissues, suggested that both $H v A C S$ and $H v A C O$ were specifically regulated by flower senescence.
\end{abstract}

Additional key words: 1-aminocyclopropane-1-carboxylic acid (ACC) synthase, ACC oxidase, expression analysis, gene cloning

\section{Introduction}

Hosta Tratt. is an herbaceous perennial with about 45 species distributed mainly in Japan, as well as a few in China, Korea and Russia (Rao et al., 2012). Hosta ventricosa is the only natural tetraploid species in the genus Hosta (Cao et al., 2011). This species has been widely used in city afforestation, garden landscape and home decoration as a globally important ornamental plant for both beautiful foliage and flowers (Shadrack and Shadrack, 2011). The main reason for its wide cultivation in China is not only for its ornamental value, but also for its consideration as a medicinal herb and its economical value as food (Cao et al., 2011). H. ventricosa is generally easy and long-lived garden plant, relatively disease free, requiring little care other than watering and some fertilizer to enhance growth (http://belflora.com/en/catalog/hosta/). This species is adichogamous and self-compatible, but pollinator visitation is necessary for pollination. Flowers are produced on a raceme inflorescence and open sequentially from basal to distal positions (acropetal blooming). Commonly, only one or two flowers open on the same day within an inflorescence. However, longevity of individual flowers is only one day (Cao et al., 2011).

Ethylene, an internal signal molecule, plays a pivotal role in flower development, senescence and abscission. Disruption of ethylene biosynthesis in carnation and petunia resulted in delayed flower death (Rogers, 2006). In higher plants, ethylene is made via a two-step biosynthetic route that starts with the conversion of the methionine derivative S-adenosyl-L-methionine to 1-aminocyclopropane-1-carboxylic acid (ACC) by ACC synthase (ACS, EC 4.4.1.14). Then ACC is oxidized by ACC oxidase (ACO) to release ethylene (Lin et al., 2009). The activity of ACS is considered to be the

\footnotetext{
*Comesponding author: yangl@zjnu.edu.cn

※ Received 29 November 2012; Revised 26 May 2013; Accepted 5 February 2014. We gratefully thank Prof. Yuanwen Teng (Zhejiang University, Hangzhou, China) for technical assistance in ethylene analysis and Dr. Min Wu (Arizona State University) for critical reading and grammatical correction of manuscript. This research was funded by the Science and Technology Department of Zhejiang Province (2004C32091) and the Zhejiang Normal University Innovative Research Team Program China.

(C) 2014 Korean Society for Horticultural Science
} 
rate-limiting step in the pathway (Wang et al., 2007), and the ACO activity contributes to the regulation of ethylene production (Lasserre et al., 1996; Xue et al., 2008). Both enzymes are encoded by multigene families, the members of which are differentially regulated in a tissue-specific manner by a variety of signals including wounding and senescence (Jones and Woodson, 1999; Lasserre et al., 1996; Lin et al., 2009; Trusov and Botella, 2006; Xue et al., 2008). Although there is evidence for the regulation of ACS and ACO at the posttranscriptional level, expression analyses indicate that the induction of their activity is most often the result of the increased accumulation of the mRNAs (Jones and Woodson, 1999; Weterings et al., 2002). The sensitivity of flower senescence to endogenously produced ethylene is species specific (Rogers, 2006). In ethylenesensitive species, flower senescence is regulated through the expression of genes encoding ACS and ACO enzymes (ten Have and Woltering, 1997). Their transcript levels are up-regulated as petals senesce (Jones, 2003; Weterings et al., 2002).

The flowers of $H$. ventricosa produce nectar and have six tepals, six stamens of similar size, and a gynoecium consisting of three carpels. They produce seed by pseudogamous apomixis (Cao et al., 2011). The role of ethylene in its flower senescence is unclear. There has been no attempt to determine if $H$. ventricosa flowers produce ethylene, nor have the related genes been cloned. An understanding of the role of ethylene in the control of floral deterioration in $H$. ventricosa has commercial relevance for post-harvest handling, as well as furthering understanding of the regulation of floral senescence. Accordingly, our main objectives in this study were to (i) evaluation on ethylene production from whole flowers and wounded leaves of $H$. ventricosa; (ii) cloning of two genes encoding the ethylene biosynthetic enzymes ACS and ACO from blooming flowers and analysis of gene sequences; and (iii) comparison of their expression during flower development with that in wounded leaves.

\section{Materials and Methods}

\section{Plant Materials}

Hosta ventricosa (Salisb.) Stearn (Hostaceae) was planted in soil and grown under natural conditions at the experimental farm at Zhejiang Normal University, China. Flowers were sampled at four flowering stages (Fig. 1): A, small bud. Petaloid tepals started to emerge from bracts; B, mature bud. Petaloid tepals reached their full length and were ready to open; C, blooming. Flower fully opened. Six stamens were visible. The anthers were all undehisced and positioned below the stigma; and D, wilting. Petaloid tepals were wilted. The flower appearance had deteriorated and all the anthers were dehisced. Stem, young leaf and root samples of $H$. ventricosa were randomly collected periodically. For gene expression analysis in wounded leaves, mature leaves were cut across the midrib with a sterile razor blade for $2 \mathrm{~h}, 6 \mathrm{~h}, 12 \mathrm{~h}$ and $24 \mathrm{~h}$. All samples were frozen immediately in liquid nitrogen and stored at $-80^{\circ} \mathrm{C}$.

\section{Measurement of Ethylene Production}

Ethylene production was measured on three replicates each of four detached whole flowers (eight for blooming flowers) or wounding leaves at the given sampling times. The samples were detached and enclosed in 50 or 280 $\mathrm{mL}$ (for blooming flowers) airtight containers and incubated at $25^{\circ} \mathrm{C}$ for $2 \mathrm{~h}$ following which $1 \mathrm{~mL}$ of the headspace was withdrawn. Ethylene concentration in the gas sample was analyzed by gas chromatography (GC; model SP 6800, Lunan Chemical Engineering Instrument, Shandong, China) equipped with a GDX-502 column and a flame-ionization detector for ethylene determination. The injector, detector, and oven/column temperatures were $110^{\circ} \mathrm{C}, 140^{\circ} \mathrm{C}$, and $90^{\circ} \mathrm{C}$, respectively.

\section{RNA and DNA Extraction and cDNA Synthesis}

Total RNA was extracted from whole flower with improved
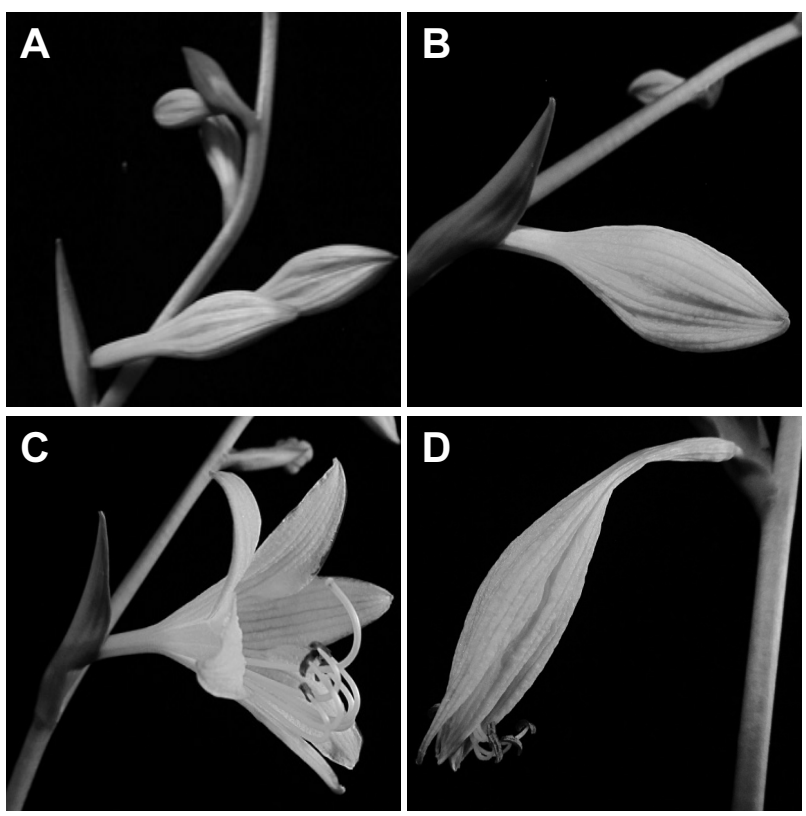

Fig. 1. Stages of $H$. ventricosa flower development. A, small bud; B, mature bud; C, blooming; D, wilting. 
hot borate method (Hunter and Reid, 2001), while that was isolated from root, stem and leaf using Trizol Reagent (Life Technologies, Carlsbad, CA, USA). Genomic DNA was extracted by cetyltriethylammnonium bromide method. The quality and concentration of RNA and DNA were checked by agarose gel electrophoresis and evaluated by a NanoDrop 2000 Spectrophotometer (Thermo Scientific, San Jose, CA, USA). First-strand cDNA was synthesized using an oligo (dT)-18 primer and Superscript II kit (Invitrogen, Carlsbad, CA, USA) according to manufacturer's instructions.

\section{Internal Conserved Fragment Cloning of Two Ethylene Biosynthetic Genes}

The primers were designed based on the conserved sequence of each gene from the National Center for Biotechnology Information (NCBI) database to amplify two gene fragments and were synthesized by SBS Genetech Co., Ltd. (Shanghai, China). The degenerated primers TA(T/C) CC(G/A/T)GGATT(T/C)GA(T/C)AGAGA and AACCA(A/T/G/C) $\mathrm{CC}(\mathrm{A} / \mathrm{C} / \mathrm{T}) \mathrm{GG}(\mathrm{T} / \mathrm{C}) \mathrm{TC}(\mathrm{G} / \mathrm{C} / \mathrm{A})(\mathrm{A} / \mathrm{G})(\mathrm{A} / \mathrm{C} / \mathrm{T}) \mathrm{GCA}$ were used for cloning of $H v A C S$ partial $c D N A$, and the specific primers 5'-GGGGCTTCTTTGAGATTCTGAACC-3' and 5'-TCATGGTCT CAAATCTTGGCTCC-3' for HvACO. $1 \mu \mathrm{L}$ of the diluted cDNA from blooming flowers was amplified in $20 \mu \mathrm{L}$ reaction mixtures containing $2 \mu \mathrm{L} 10 \times \mathrm{PCR}$ buffer with $\mathrm{MgCl}_{2}, 2 \mu \mathrm{L}$ $2.5 \mathrm{mM}$ dNTPs, $0.2 \mu \mathrm{L}$ rTaq polymerase (Takara, Dalian, China), $0.5 \mu \mathrm{L} 10 \mu \mathrm{M}$ each primer and $13.8 \mu \mathrm{L}$ distilled $\mathrm{H}_{2} \mathrm{O}$. The PCR was conducted for 30 cycles each consisting of $30 \mathrm{~s}$ at $95^{\circ} \mathrm{C}, 30 \mathrm{~s}$ at $52^{\circ} \mathrm{C}$ or $55^{\circ} \mathrm{C}$ and $1 \mathrm{~min}$ at $72^{\circ} \mathrm{C}$. Purified amplified products of appropriate length were ligated to the pMD18-T vector for sequencing (Sangon, Shanghai, China).

\section{5'- and 3'-RACE (the Rapid Amplification of cDNA Ends) of $H_{v} A C S$ and $H v A C O$}

The 5'- and 3'-RACE cDNAs of two genes were isolated according to the SMART RACE cDNA Amplification Kit protocol (Clontech, Mountain View, CA, USA). For HvACS we used the specific primer 5'-GAACTCCTCATCAGACAACA TTGAGGC-3' and UPM for the first round of 5'-RACE, and 5'-CACCGAGGCTTCAGCCGCAAAGATCAC-3' and UPM for 3'RACE both at the annealing temperature of $58.5^{\circ} \mathrm{C}$. The PCR product was diluted 40 -fold as a template for the second round. The nested primer (5'-CGATCACGAAGTCGA GTGCATCTTCGAGG-3') and NUP (provided in the kit) were used for $5^{\prime}$-RACE at the annealing temperature of $59.2^{\circ} \mathrm{C}$, 5 '-CTCGGGGGTACGACAACGCAGAGAGAGTCC-3' and NUP for $3^{\prime}$-RACE at the annealing temperature of $61.0^{\circ} \mathrm{C}$. The 20 $\mu \mathrm{L}$ reaction mixture was subjected to an initial denaturation at $95^{\circ} \mathrm{C}$ for $5 \mathrm{~min}$, and subsequently 30 cycles of amplification $\left(95^{\circ} \mathrm{C}\right.$ for $30 \mathrm{~s}$, annealing for $30 \mathrm{~s}$ and $72^{\circ} \mathrm{C}$ for $1 \mathrm{~min}$ )

For $H v A C O$, the first round of amplification was performed using the specific primer 5'-GGACTCGGGGAGATGGCGCAAG AAG-3' and UPM for 5'-RACE at the annealing temperature of $58.0^{\circ} \mathrm{C}$, and $5^{\prime}$-GGGGCTTCTTCGAGATGGTGAACCACGGAA-3' and UPM for $3^{\prime}$-RACE at the annealing temperature of $56.5^{\circ} \mathrm{C}$. The nested primer ( 5 -TTGCTCCATGCCCTTCTTGTA GTGCCCC-3') and NUP (provided in the kit) were used for $5^{\prime}$-RACE at the annealing temperature of $57.2^{\circ} \mathrm{C}, 5^{\prime}$-CTTCTT GCGCCATCTCCCCGAGTCCAACAT-3' and NUP for 3'-RACE at the annealing temperature of $58.0^{\circ} \mathrm{C}$. All RACE products were ligated to the pMD18-T vector for sequencing.

\section{Cloning of the Full-length cDNAs and DNAs of HvACS and HvACO}

After alignment and assembly of the sequences of the internal conserved sequence, the 5'-RACE and 3'-RACE products, the full-length cDNA seqences of two genes were deduced and subsequently obtained by RT-PCR in a total volume of $20 \mu \mathrm{L}$. The primers 5'-GGCCTTCTCTTAATATTTC ATTAGTTGTG-3' and 5'-AACAAGACTGGATGCATAATTACG ATCC-3' were used for HvACS, 5'-ACGCGGGGACAACACAAG CACTAA-3' and 5'-AGTAGCTCATGATCAACAACACTTA-3' for $H v A C O$. The PCR annealing temperature was $60.5^{\circ} \mathrm{C}$ for $H v A C S$ and $54.6^{\circ} \mathrm{C}$ for $H v A C O$. And the extension time was 2 min instead of $1 \mathrm{~min}$.

The full-length DNAs of two genes were amplified using genomic DNA from leaves as templates and the same primers as above for HvACS, and 5'-GCCATGGACGTTCTTC GTGATGCTTGCGAG-3' and 5'-CACTTATGAGTCTCTCTCTC TCTCATGCAG-3' for $H v A C O$ at the annealing temperature of $61.5^{\circ} \mathrm{C}$.

\section{Sequence Analysis}

Nucleotide sequence and the deduced amino acid sequence were identified by the NCBI BLAST program (http://www. ncbi.nlm.nih.gov/BLAST/). Prediction of ORF was made using the NCBI ORF Finder program. The full-length cDNA and DNA sequences were assembled with ContigExpress software (Invitrogen, Carlsbad, CA, USA). Gene structure was analyzed using the GSD Server (http://gsds.cbi.pku. edu.cn/index.php). Amino acid multiple alignments were made with the Clustal X 2.0 program under default parameters. Theoretical molecular weight of deduced polypeptide was calculated using the Compute Mw tool (http://www. expasy.ch/tools/pi_tool.html). Predictions of subcellular localization of the deduced polypeptides were conducted by using PSORT (http://wolfpsort.org) and TargetP (http:// 
www.cbs.dtu.dk/services/TargetP/).

\section{Semi-quantitative RT-PCR Assay}

Semi-quantitative RT-PCRs were performed using the primers 5'-CACCGAGGCTTCAGCCGCAAAGATCAC-3' and 5'GAACTCCTCATCAGACAACATTGAGGC-3' for HvACS at the annealing temperature of $59.5^{\circ} \mathrm{C}$, and $5^{\prime}$-TGAACCACGGAAT CTCGC-3' and 5'-AGCCATTGAAGGCACTCT-3' for HvACO at the annealing temperature of $55.0^{\circ} \mathrm{C}$. HvActin (Accession No. JX274300) mRNA was tested for control purposes using the primers 5'-GAACTGGTATGGTCAAGGCTG-3' and 5'-ACACGGAGCTCGTTGTAGAAG-3' at the annealing temperature of $52.0^{\circ} \mathrm{C}$. PCR amplification was performed in duplicates in three independent assays for 30 cycles with denaturation at $95^{\circ} \mathrm{C}$ for $30 \mathrm{~s}$, annealing for $30 \mathrm{~s}$ and elongation at $72^{\circ} \mathrm{C}$ for $30 \mathrm{~s}$, followed by $72^{\circ} \mathrm{C}$ for $10 \mathrm{~min}$. The relative expression was given by a ratio between the target gene and the reference gene.

\section{Results}

\section{Ethylene Production by Whole Flowers and Wounded Leaves}

In small buds of $H$. ventricosa, the level of ethylene production was approximately $85 \mathrm{~nL} \cdot \mathrm{g}^{-1} \cdot \mathrm{h}^{-1}$, which is much higher than other ethylene-sensitive species such as carnation (ten Have and Woltering, 1997) and Alstroemeria (Wagstaff et al., 2005). Ethylene concentration increased significantly ( $p$ $<0.01$ ) at blooming stage to a maximum over $450 \mathrm{~nL} \cdot \mathrm{g}^{-1} \cdot \mathrm{h}^{-1}$ and thereafter declining slightly to $365 \mathrm{~nL} \cdot \mathrm{g}^{-1} \cdot \mathrm{h}^{-1}$ at wilting stage (Fig. 2A). The increase in ethylene production occurred before symptoms of senescence were apparent.

As shown in Fig. 2B, the ethylene production was significantly $(p<0.01)$ enhanced at $6 \mathrm{~h}$ after mechanical wounding in mature leave, and seemed to decline at a similar rate to that at which it increased.

\section{Isolation and Characterization of $H_{v} A C S$ and $H_{v} A C O$ from $H$. ventricosa Flowers}

On the basis of the conserved amino acid sequences of two genes from different plant species, two pairs of primers were designed. Two cDNA fragments of $777 \mathrm{bp}$ and 822 bp were obtained by PCR using CDNA aliquots of blooming flowers of $H$. ventricosa. To clone the full-length cDNA, 3'and 5'-RACE reactions were conducted. The 5'-RACE-PCRs generated a fragment of $771 \mathrm{bp}$ for the HvACS and $274 \mathrm{bp}$ for the HvACO gene. 3'-RACE reactions generated fragments of $702 \mathrm{bp}$ and $1071 \mathrm{bp}$ for $H v A C S$ and $H v A C O$, respectively. On the basis of the above sequences, specific primers were designed for the 3'- and 5'-untranslated regions of two genes, and the full-length cDNA and genomic DNA were amplified.

The cloned HvACS was $1562 \mathrm{bp}$ in length and contained a 1347 bp ORF encoding a protein of 448 amino acids. The calculated molecular mass of the protein was 49.9 $\mathrm{kDa}$ with an isoelectric point of 5.81 (Table 1). The putative protein had a high identity with other known from Musa acuminata (CAA11158.1) (79\%). Seven highly conserved regions among all ACS were detected in HvACS (Fig. 3). The Lys276 present in the most heavily conserved region serves as the pyridoxal 5'-phosphate (PLP)-binding site by reducing the double bond between PLP and the enzyme

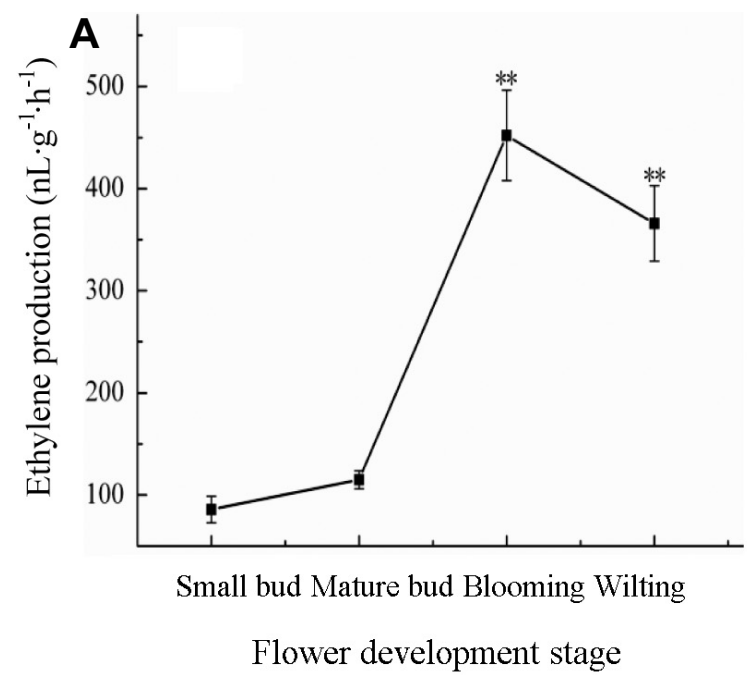

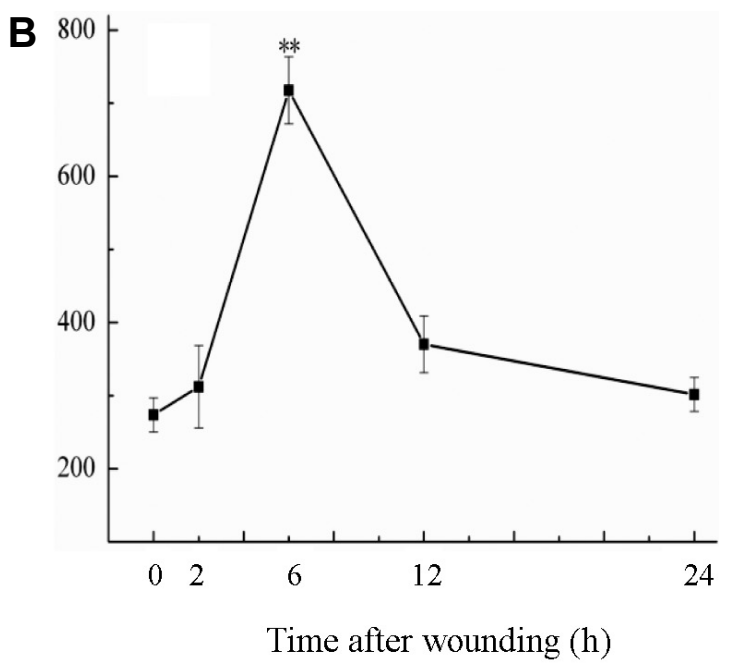

Fig. 2. Ethylene production from H. ventricosa flowers (A) and wounded leaves (B). Error bars indicate SE from three replicates. 
Table 1. Description of two full-length genes encoding ethylene biosynthetic enzymes from $H$. ventricosa flower.

\begin{tabular}{lccccccc}
\hline Gene & $\begin{array}{c}\text { Accession } \\
\text { No. }\end{array}$ & $\begin{array}{c}\text { Full-length DNA } \\
\text { (bp) }\end{array}$ & $\begin{array}{c}\text { Full-length cDNA } \\
\text { (bp) }\end{array}$ & $\begin{array}{c}\text { ORF } \\
\text { (bp) }\end{array}$ & $\begin{array}{c}\text { Encoded } \\
\text { amino acid }\end{array}$ & $\begin{array}{c}\text { Protein molecular } \\
\text { mass (kDa) }\end{array}$ & $\begin{array}{c}\text { Isoelectric } \\
\text { point }\end{array}$ \\
\hline HvACS & JX274302 & 1915 & 1562 & 1347 & 448 & 49.9 & 5.81 \\
HvACO & JX274303 & 1611 & 1152 & 957 & 318 & 36.1 & 5.14 \\
\hline
\end{tabular}

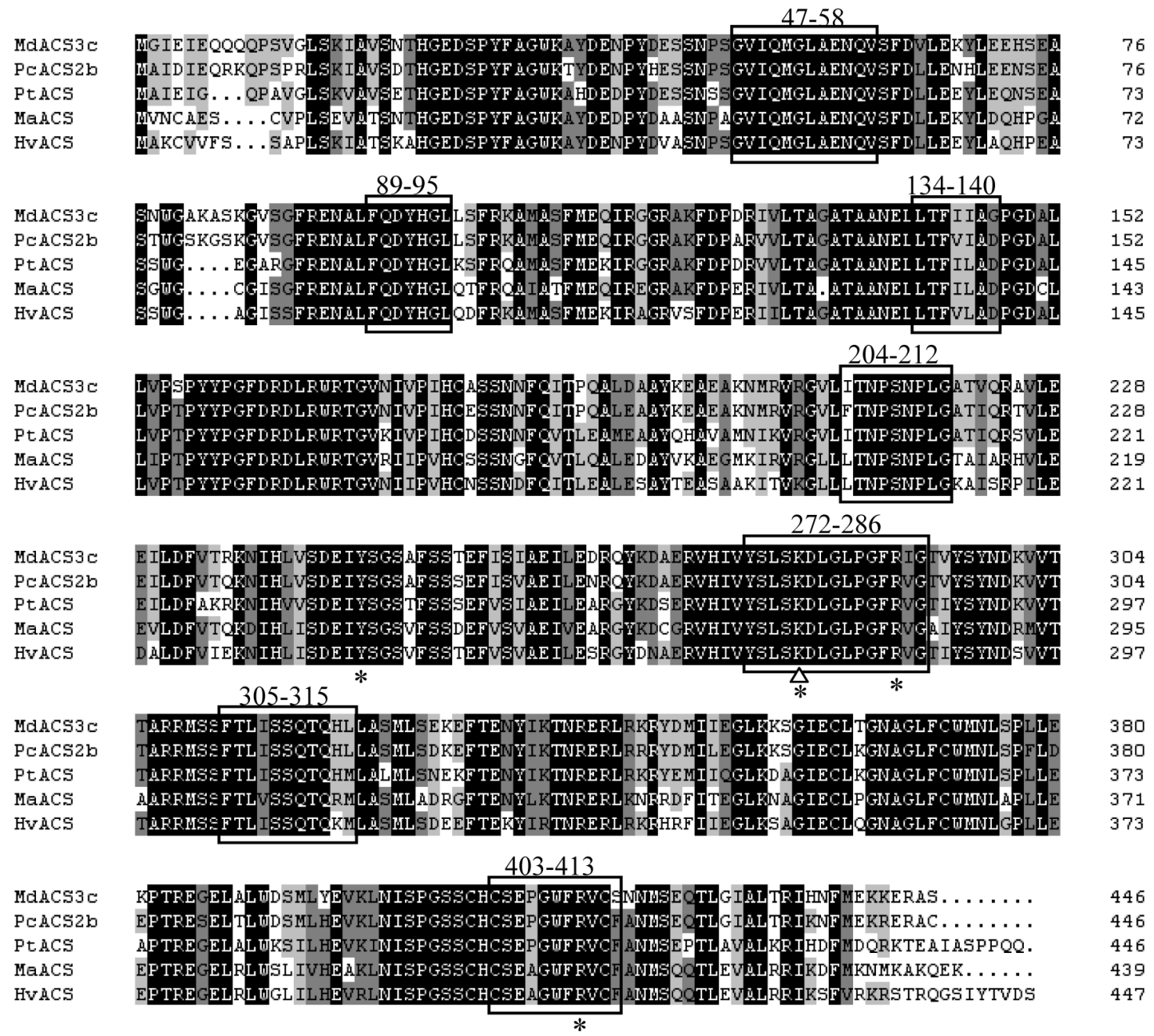

Fig. 3. Alignment of HvACS with most closely related ACS from Malus domestica (BAE94692.1), Pyrus communis (AAR38503.1), Populus trichocarpa (EEF09581.1), and M. acuminata (CAA11158.1). The identical amino acids were shaded in dark and the well-conserved residues were shaded in gray. Seven conserved motifs of all ACSs are boxed. The triangle indicates the active site Lys276. Four residues which have been studied by site-directed mutagenesis in apple and tomato ACS are marked by asterisk.

itself in tomato (Lin et al., 2009). Eleven invariant residues that were conserved in all ACS and certain aminotransferase (Wang et al., 2007) also present in HvACS. Four important amino acid residues (Tyr240, Lys276, Arg284 and Arg410) were detected here (Fig. 3), which were involved in interactions with the PLP cofactor in apple and tomato (Wang et al., 2007). The C-terminal end, the least conserved region, may correspond to the different protein dimerization and stability of ACS (Wang et al., 2007). The genomic sequence of HvACS was 1915 bp and interrupted by two introns (257 bp and $643 \mathrm{bp}$ respectively) located near the 5'-end of gene, similar to ACS genes from other higher plants 
(Wang et al., 2007).

The full-length $\mathrm{HvACO}$ harbored an ORF of $957 \mathrm{bp}$ encoding a polypeptide of 318 amino acids with calculated molecular mass $36.1 \mathrm{kDa}$ (Table 1). The HvACO amino acid sequence showed $83 \%$ identity with ACO of Narcissus tazetta (AEZ06406.1). Seven regions indicated in box (Fig. 4) were conserved in other ACO isoforms. The nine amino acid residues (Pro5, Ala27, His39, His177, Asp179, Gly218, His234, Arg244 and Ser246) (Fig. 4) conserved across all members of the $\mathrm{Fe} /$ ascorbate-dependent dioxygenase family (Lasserre et al., 1996) were found in HvACO. Three residues (His177, Asp179 and His234) were ligated to a single Fe(II) to form the active site. The side chains of Arg175 and Arg244 were involved in binding bicarbonate, which leads to the activation of the ACO enzyme (Zhang et al., 2004).
HvACO is similar to the tomato, petunia and melon genes, with three introns located at the responding positions (Lasserre et al., 1996).

Expression of Two Ethylene Biosynthetic Genes during Flower Development and in Wounded Leaves

In flowers, the HvACS transcript was below the level of detection at small bud stage and at mature bud stage, strongly induced at blooming stage and remained at moderate level at wilting stage (Fig. 5A). The relative expression of $H v A C O$ significantly increased $(p<0.01)$ by over 2.2 -fold at blooming stage and 1.5-fold at wilting stage compared to small bud stage (Fig. 5C). The maximum expression of $H v A C S$ and $H v A C O$ was observed at blooming stage which was accompanied by a peak of ethylene production (Fig. 2).

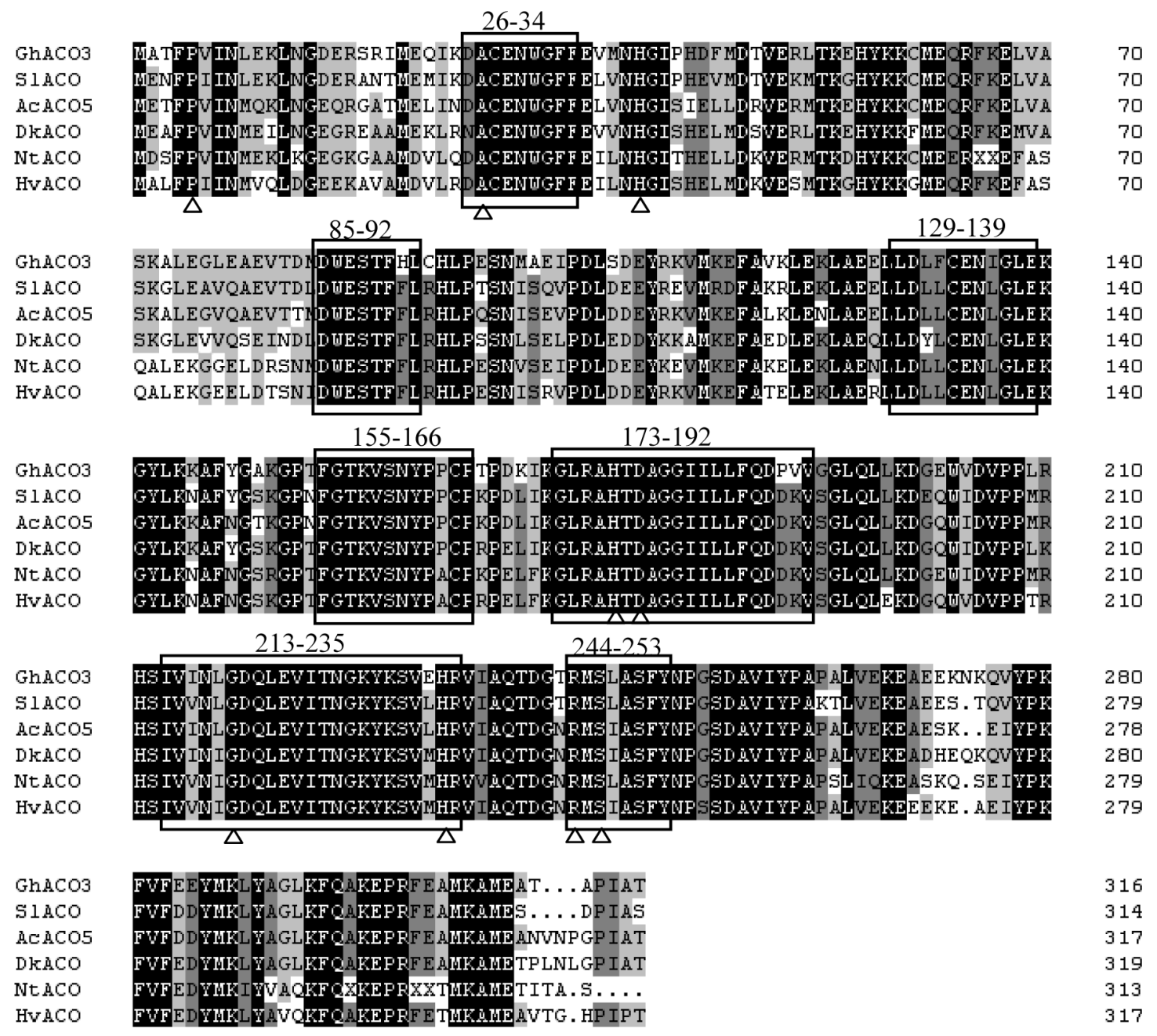

Fig. 4. Alignment of amino acid sequences deduced from ACO genes of Gossypium hirsutum (AAZ83344.1), Solanum lycopersicum (AD032577.1), Actinidia chinensis (AEM62883.1), Diospyros kaki (BAB89352.1), and Narcissus tazetta (AEZ06406.1). The identical amino acids were shaded in dark and the well-conserved residues were shaded in gray. The seven conserved motifs are boxed. Nine amino acids conserved in all members of the Fe(II) ascorbate family of dioxygenases are indicated with triangle. 

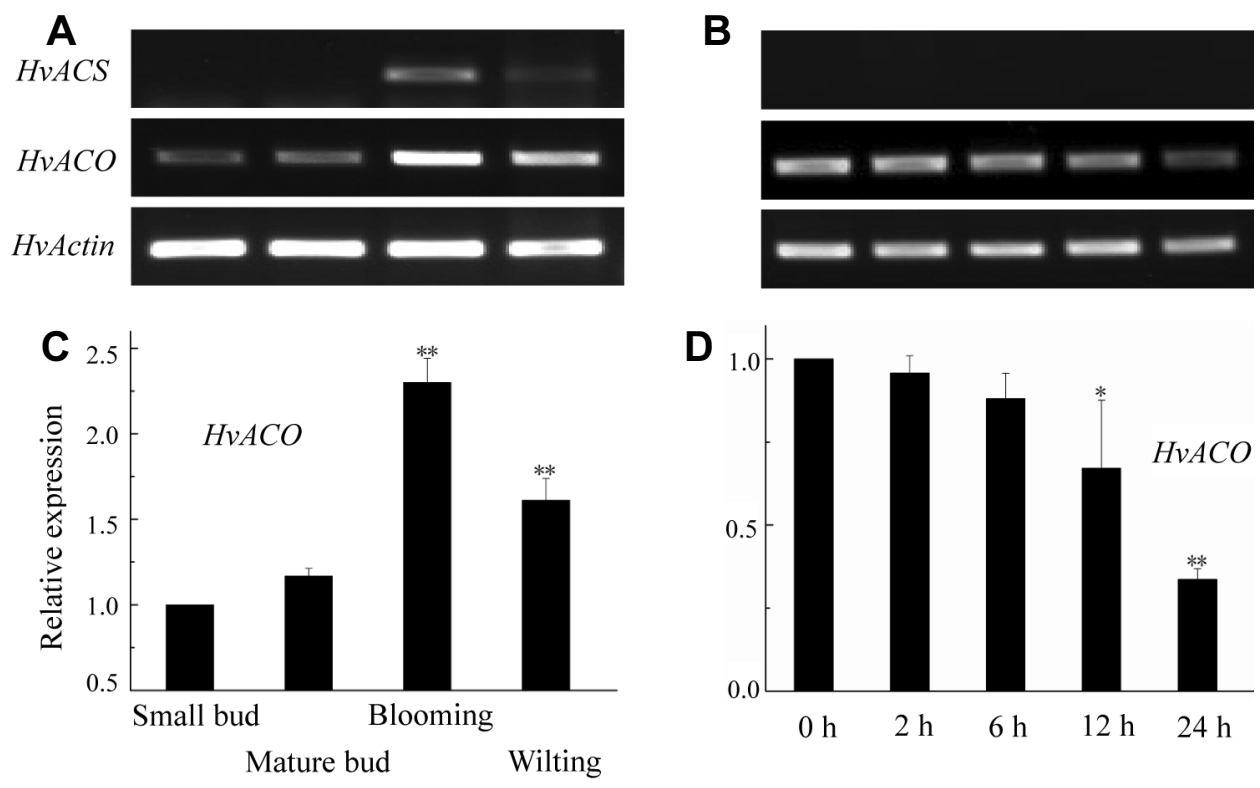

Fig. 5. Temporal expression analysis of $H v A C S$ and $H v A C O$ in the flowers (A, C) and in the wounded leaves (B, D) of $H$. ventricosa. (C, D) Relative mRNA levels relative to HvActin levels. Three replicates were averaged and the standard deviation is shown.

In wounded leaves, there were not much changes in HvACO expression within $6 \mathrm{~h}$, but a significant decrease after $12 \mathrm{~h}$ of treatment (Fig. 5D). Interestingly, the HvACS transcript was not detected throughout the 24-h period after mechanical wounding (Fig. 5B).

\section{Discussion}

Flower deterioration of $H$. ventricosa is manifested as tepal wilting (Fig. 1). There was a significant increase in the rate of ethylene production from blooming and wilting flowers (Fig. 2). The expression analyses of two cloned genes involved in ethylene biosynthesis indicated that the timing of the induction of HvACS expression was correspond to the timing of the increase of ethylene production, and that the up-regulation of $H v A C O$ transcript was closely correlated with elevated ethylene production. In order to determine whether the accumulation of HvACS and HvACO mRNAs identified from whole flowers were flower-specific, the expression of two genes was also investigated in the wounded leaves that stimulated the generation of ethylene, and in different vegetative tissues. HvACS transcripts were detectable only in stems and roots (Fig. 6), and strongly induced in blooming and wilting flowers (Fig. 5A), whereas not detectable in young leaves and in wounded mature leaves (Fig. 5B). The results indicated that HvACS exclusively expressed during flower senescence. The transcripts of $H v A C O$, which were present in flowers and young leaves

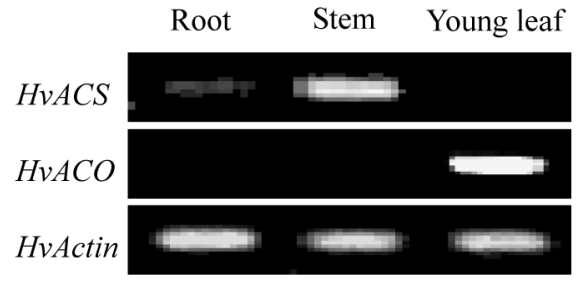

Fig. 6. Expression of $H v A C S$ and $H v A C O$ in vegetative tissues of $H$. ventricosa.

and not in roots and stems (Figs. 5A and 6), displayed a significant up-regulation during the late stages of flower development from a basal level (Fig. 5C) but underwent a down-regulation at $12 \mathrm{~h}$ and $24 \mathrm{~h}$ after wounding in mature leaves (Fig. 5D). These data suggested that HvACS and $H v A C O$ here were specifically regulated by flower senescence although they are encoded by multigene family (Lin et al., 2009), and ethylene played an important role in flower senescence of $H$. ventricosa. There are likely additional members of HvACS and HvACO gene family responsible for the responses to wounding in mature leaves.

$A C S$ and $A C O$ have been reported in several species to be involved in flower development or senescence. In rose, the expression of the ACS gene increased in a short-lasting cultivar, but remained at a constant and low level in a long-lasting one during the petal senescence process of flower, while the expression of the $A C O$ gene increased in the final stage of flower development in both cultivars 
(Müller et al., 2000). In tobacco, both ACS2 and ACO transcripts were not detected at early flower stage and the levels increased at later stages when ethylene release was induced by the pistil (Weterings et al., 2002). In Alstroemeria, ALACO1 showed very little change over the first six stages of development, but then increased by over 4.5 -fold in the last two stages of development prior to tepal abscission (Wagstaff et al., 2005). In tomato, pollination caused an increase in ethylene synthesis, an enhanced rate of senescence, and was accompanied by changes in ACS and ACO expression (Llop-Tous et al., 2000). In carnation, the abundance of $A C S$ and $A C O$ mRNAs increased concomitantly with the ethylene climacteric in senescing petals (ten Have and Woltering, 1997; Woodson et al., 1992). Continuous monitoring of the flowering dynamics of transgenic and control pineapple plants showed that suppression of the ACS2 gene resulted in significantly delayed flowering (Trusov and Botella, 2006). Flowers of transgenic carnation containing antisense $A C O$ gene exhibited low climacteric ethylene production and a markedly delayed petal senescence (Savin et al., 1995).

In carnation, ethylene produced from the pollinated stigma is translocated, via the style and ovary, to the petals. Here it up-regulates ethylene biosynthetic genes and induces the production of ethylene in the petals (ten Have and Woltering, 1997). Once initiated, the production of ethylene becomes autocatalytic (Wagstaff et al., 2005). In tomato, translocated ACC from the pistil may be important for regulating the initial burst of ethylene production during petal senescence (Llop-Tous et al., 2000). Further detailed study will be needed to more accurately identify the site of ethylene biosynthesis, and assess the regulatory mechanisms of ethylene biosynthesis in the senescing flower of $H$. ventricosa.

\section{Literature Cited}

Cao, G., L. Xue, Y. Li, and K. Pan. 2011. The relative importance of architecture and resource competition in allocation to pollen and ovule number within inflorescences of Hosta ventricosa varies with the resource pools. Ann. Bot. 107:1413-419.

Hunter, D.A. and M.S. Reid. 2001. A simple and rapid method for isolating high quality RNA from flower petals. Acta Hort. 543:147-152.

Jones, M.L. 2003. Ethylene biosynthetic genes are differentially regulated by ethylene and ACC in carnation styles. Plant Growth Regul. 40:129-138.

Jones, M.L. and W.R. Woodson. 1999. Differential expression of three members of the 1-aminocyclopropane-1-carboxylate synthase gene family in carnation. Plant Physiol. 119:755-764.

Lasserre, E., T. Bouquin, J.A. Hernandez, J. Bull, J.C. Pech, and
C. Balagué. 1996. Structure and expression of three genes encoding ACC oxidase homologs from melon (Cucumis melo L.). Mol. Gen. Genet. 251:81-90.

Lin, Z., S. Zhong, and D. Grierson. 2009. Recent advances in ethylene research. J. Exp. Bot. 60:3311-3336.

Llop-Tous, I., C.S. Barry, and D. Grierson. 2000. Regulation of ethylene biosynthesis in response to pollination in tomato flowers. Plant Physiol. 123:971-978.

Müller, R., S. Lind-Iversen, B.M. Stummann, and M. Serek. 2000. Expression of genes for ethylene biosynthetic enzymes and an ethylene receptor in senescing flowers of miniature potted roses. J. Hort. Sci. Biotech. 75:12-18.

Rao, G., Y. Wang., D. Zhang, D. Liu, F. Li, and H. Lu. 2012. Isolation and characterisation of an HpSHP gene from Hosta plantaginea. Mol. Biol. Rep. 39:6887-6894.

Rogers, H.J. 2006. Programmed cell death in floral organs: How and why do flowers die? Ann. Bot. 97:309-315.

Savin, K.L., S.C. Baudioette, M.W. Graham, M.Z. Michael, G.D. Nugent, C.Y. Lu, S.F. Chandler, and E.C. Cornish. 1995. Antisense ACC oxidase RNA delays carnation petal senescence. HortScience 30:970-972.

Shadrack, K.G. and M. Shadrack. 2010. The book of little Hostas: 200 small, very small, and mini varieties. Timber Press, USA.

ten Have, A. and E.J. Woltering. 1997. Ethylene biosynthetic genes are differentially expressed during carnation (Dianthus caryophyllus L.) flower senescence. Plant Mol. Biol. 34:89-97.

Trusov, Y. and J.R. Botella. 2006. Silencing of the ACC synthase gene $A C A C S 2$ causes delayed flowering in pineapple [Ananas comosus (L.) Merr.]. J. Exp. Bot. 57:3953-3960.

Wagstaff, C., U. Chanasut, F.J. Harren, L.J. Laarhoven, B. Thomas, H.J. Rogers, and A.D. Stead. 2005. Ethylene and flower longevity in Alstroemeria: Relationship between tepal senescence, abscission and ethylene biosynthesis. J. Exp. Bot. 56:1007-1016.

Wang, X., Y. Zhang, J. Zhang, C. Cheng, and X. Guo. 2007. Molecular characterization of a transient expression gene encoding for 1-aminocyclopropane-1-carboxylate synthase in cotton (Gossypium hirsutum L.). J. Biochem. Mol. Biol. 40:791-800.

Weterings, K., M. Pezzotti, M. Cornelissen, and C. Mariani. 2002. Dynamic 1-aminocyclopropane-1-carboxylate-synthase and -oxidase transcript accumulation patterns during pollen tube growth in tobacco styles. Plant Physiol. 130:1190-1200.

Woodson, W.R., K.Y. Park, A. Drory, P.B. Larsen, and H. Wang. 1992. Expression of ethylene biosynthetic pathway transcripts in senescing carnation flowers. Plant Physiol. 99:526-532.

Xue, J., Y. Li, H. Tan, F. Yang, N. Ma, and J. Gao. 2008. Expression of ethylene biosynthetic and receptor genes in rose floral tissues during ethylene-enhanced flower opening. J. Exp. Bot. 59:21612169.

Zhang, Z., J.S. Ren, I.J. Clifton, and C.J. Schofield. 2004. Crystal structure and mechanistic implications of 1-aminocyclopropane1-carboxylic acid oxidase-the ethylene-forming enzyme. Chem. Biol. 11:1383-1394. 